\title{
How Did the 2015 Political Crisis Affect Nepal in Economic and Social Respects?
}

\author{
Ryotaro Shimizu $^{1, *}$, Brenda Bushell ${ }^{2}$, Masayuki Goto ${ }^{1}$ \\ ${ }^{1}$ School of Create Science and Engineering, Waseda University, Japan \\ ${ }^{2}$ Faculty of Liberal Arts, the University of the Sacred Heart, Japan
}

Copyright $\bigcirc 2018$ by authors, all rights reserved. Authors agree that this article remains permanently open access under the terms of the Creative Commons Attribution License 4.0 International License

\begin{abstract}
In 2015, Nepalese people faced two serious problems: a number of massive earthquakes, and a political crisis. After the end of the civil war in 2006, the Nepalese government worked for several years on drafting the new constitution; however, it could not be realized due to political disagreements. Triggered by a massive earthquake in April 2015, the general opinion was to establish the constitution, and it was finally ratified in September, 2015. However, it was not accepted by the Madhesi, one of the communities in Nepal that has its origins in India. As a result, the transportation of supplies from India was blocked at the border between India and Nepal for several months. Nepalese people could not buy gas, oil and other commodities. The media reported that the Nepalese economy was strongly impacted by the chain of these events, as a result of this political crisis. For contributing to the future development of Nepal, it is meaningful to properly evaluate and record the impact of such political turmoil on the economy and the lives of the general public. In this research, we investigate the influence and impacts of this crisis. It was not merely the lack of the new Nepalese Constitution that caused the political crisis, but by the lack of oil which paralyzed economic activities in Nepal. This situation strongly impacted the lives of all Nepalese. Through analysis of data from field interviews, we identify the influences of the political crisis on the daily life of Nepalese people in Kathmandu and Sauraha. Through the field interviews, the influences on the economic and social sectors are clarified. For example, we found that the political crisis made Nepalese feel some inconvenience in their lives, regardless of sex, job, caste, and etc. In addition, it became clear that there was an overall lack of citizens' consciousness of the parties leading up to the political crisis. Adding to these findings, this paper reports the recognition of the situation at the time in Nepal, clarified by the field survey. We discuss and consider the best solution for these problems from several different viewpoints.
\end{abstract}

Keywords Nepal, Political Crisis, the New
Constitution, Developing Country, Tourism Industry

\section{Introduction}

Nepal is one of the least developed countries in South Asia. Landlocked between China and India, it is rich in animal and plant diversity and boasts of Mount Everest and the Himalayan mountain range. On May $12^{\text {th }}$ 2015, an earthquake with a magnitude of 7.8 occurred and killed nearly 9,000 people, injuring nearly 22,000 people [1], [2]. It made hundreds of thousands of Nepalese homeless with entire villages flattened across many districts of the country [3],[4],[5]. Needless to say, the earthquake gave the Nepalese a great deal of mental and physical despair. However, not only this massive earthquake occurred, but also a political crisis.

After the end of the civil war in 2006, the Nepalese government began drafting a new constitution; however, it could not be realized due to political disagreements. Triggered by a massive earthquake in April 2015, the general opinion was to establish the constitution, and it was finally ratified in September, 2015. However, the Madhesis, an ethnic minority originating from India and residing in Nepal near the border with India rebelled, believing the new constitution was discriminatory against them. As a result, they staged a 135-day blockage of vital supplies from India. While under this crisis, Nepalese people could not buy gas, oil and other commodities. The media reported that the Nepalese economy was strongly impacted by the chain of these events as a result of this political crisis [6],[7],[8]. Such a crisis can be a fatal blow for developing countries such as Nepal, and the possibility that a similar crisis like this will occur again is greatly conceivable. For the purpose of contributing to the future development of Nepal, it is meaningful to properly evaluate and record the impact of such political turmoil on the economy and the lives of the general public. In addition, it is also important 
to not only evaluate the economic and social impact from a macro perspective, but also to evaluate exactly how the communities of Nepal and the lives of individual citizens have been influenced. In this research, we investigate the influence and impacts of this crisis on local societies and the livelihoods of the people residing there.

Specifically, we investigate the impact and perception of the political crisis and report differences of people's opinions from various perspectives such as region, ethnicity, sex and education. Ultimately, from this investigation, we analyze the influences of the political crisis and examine the possible solutions from several viewpoints.

\section{Objectives}

In this research, we aim to identify points where the Nepalese were particularly hard hit by this political crisis. Therefore, we clarify the difference between the damaged side and undamaged side. In addition, we aim to clarify the difference between those who feel that they were affected and those who do not. In addition, we investigate the understanding and perception of local people concerning the political crisis, and consider what Nepalese can do to reduce the influence from the political crisis, or prevent the recurrence.

To achieve these goals, we designed an interview questionnaire to be conducted in various localities (see Appendix 1). It includes the following question items: (1) Question items to grasp the impacts on people's lives, (2) Question items to grasp the degree of impact of the political on each industry in Nepal, (3) Question items to grasp the people's understanding of the political crisis. Then, according to responses from the local people, we identify the real problems of the situation in Nepal and the future problems.

Specifically, category (1) includes the question items about the personal economic and social economic conditions. Category (2) includes the questions connected to agriculture, commerce and tourism. In Nepal, these industries play vital roles in the economic development of the country [9],[10],[11]. In category (3), we made the question items binary variables: it means people have to answer "Yes" or "No". By adopting such a simple structure, it reduces errors that may be caused by the different interpretations due to external factors such as educational level among respondents [12], [13].

In addition, with respect to all questions from (1) to (3), we observe whether differences appear in response trends according to demographic attributes such as sex, caste and job. This aims to clarify important factors indispensable for the development of Nepal in the situation at that time.

By the statistical analysis from the answers of the field interview, we consider not only the situation but also the main problems. Finally, we consider the future tasks that contribute to the development of Nepal.

\section{Literature Review}

Regarding the studies related to the political crisis in Nepal, several studies have been reported. For example, Singh et al. [14] focus on the aspect of politics and suggest the solution of the political crisis from a political standpoint. In this research, it is mentioned that India needs to understand that Nepal is in the phase of transition from a feudal autocracy and monarchy to democratic and republic institution. In other words, this research is highlighting the reasons for a trust deficit between Indian and Nepal, and there is a claim that India needs to show an understanding of this transition. In addition, based on investigation of the literature and a few real cases, Budhathoki et al. [15] focus on the aspect of the health of local residents during the political crisis. This research mentions that the lack of fuel has a negative impact on people's health. For example, it is stated that public services such as ambulances cannot be operated due to a lack of fuel, and as a result, lives have been lost. And finally, it is insisted that the ongoing crisis at that time in Nepal may benefit countries facing similar conditions in the future. The global health community should pay close attention to blockades and fuel crises. Gurung [16] conducted interview surveys in several communities in the southern part of Nepal, investigating their reactions to the Madhesis, and the opinions people have about the political situation. This study was focused on the Madesis behavior and action that occurred in 2015. Analysis suggest that the government should deal withthe situation proactively to resolve the Madhesis grievances with political discussions and dialogues rather than reactively with force and coercion.

In relation to this paralyzing situation in Nepal, research from other Asian countries facing similar ethnic, economic and political contention may be helpful. Basri [17] investigated the 2008 financial crisis in Indonesia. This paper argued that the structure of trade played an important role in the 2008 crisis. In detail, it is stated that due to the delay of Indonesia's integration into the global and regional networks of production, its trade dependence was lower than other Southeast Asian counties. As a result, this paper stated that the impact from the 2008 global economic crisis was small. In addition, Phaktanakul et al. [18] argues that the political crisis in Thailand in recent years arose because of the lack of effective and democratically legitimate mechanisms. The government in Thailand has tended to implement controversial policies without listening to criticisms or concerns from the minority by claiming that it received a mandate from the Thai people through the election to take action. The solution stated in this research is to empower Thai citizens to express their will on significant or controversial issues through a referendum. 
However, there are no other studies which interview local residents living in multiple areas in Nepal directly, investigating the influence of the political crisis, and analyzing their feelings and opinions. In our research, we examine what kinds of approaches can be taken for the real problems. This research allows us to propose a direct approach that will lead to the resolution of the real problems, a point which has not been done in existing research.

\section{Method of the Field interview}

In order to identify the impact of the political crisis and the resultant real problems, we developed an interview questionnaire to investigate the ongoing political crisis at the time. We conducted the interviews with a team of 35 people, consisting of Nepalese and Japanese university students. Nepalese students carried out the interviews in Nepalese, translating the responses to English. The research was conducted in the capital city Kathmandu as well as in rural villages in the Chitwan district close to the area where the blockades occurred. The research was carried out on March $7^{\text {th }}, 9^{\text {th }}, 10^{\text {th }}, 13^{\text {th }}$ and $15^{\text {th }}$ in 2016. Through the method of random sampling, we interviewed a total of 304 people.

\section{Results and Discussion}

We targeted a total of 304 respondents both male and female in both rural and urban areas, including shopkeepers, restaurant employees, hotel staff, students, farmers and others. We focused on the impact and perception of the political crisis and differences in people's opinions from various perspectives such as region, ethnicity, jobs and sex.

The ratios of sex, caste, region, job category in this field study are shown in Figures 1 to 4 . Figure 1 shows the distribution of jobs of the respondents. These 3 jobs represent the main sectors of employment in Nepal. Figure 2 shows the distribution of sex of the respondents. The percentage of males is slightly higher. Figure 3 shows the distribution of regions of the respondents. This survey was conducted in two locations: the capital Kathmandu and Chitwan National Park at the border between India and Nepal. The survey responses were approximately equal- $50 \%$ from both locations. Figure 4 shows the distribution of caste of the respondents. In this survey we were able to obtain responses from the following castes: Brahmin, Newar and Chetri. These castes are relatively high castes in Nepal. However, basically, in these 3 castes, Brahmin is the highest caste and Newar or Chetri are lower castes [19], [20].

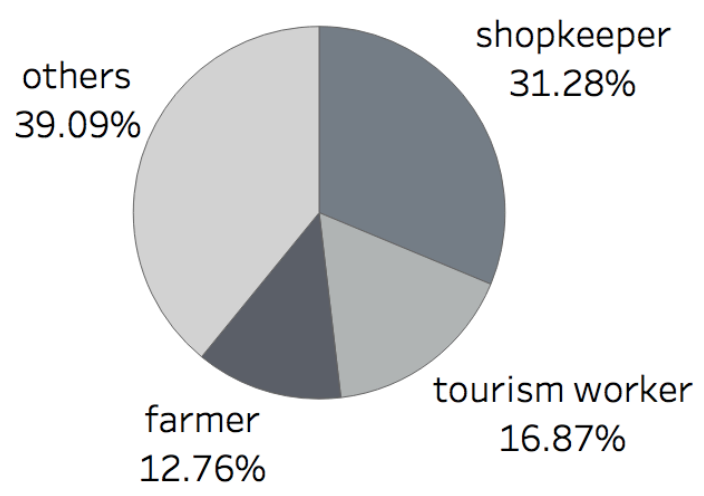

Figure 1. Distribution of the respondents according to job

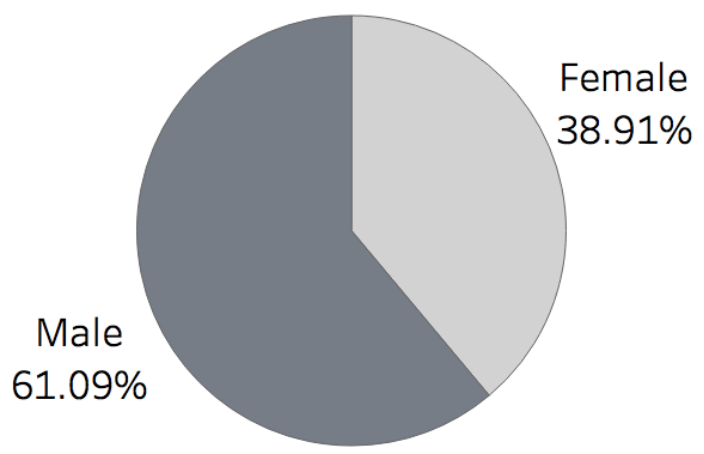

Figure 2. Distribution of the respondents according to sex

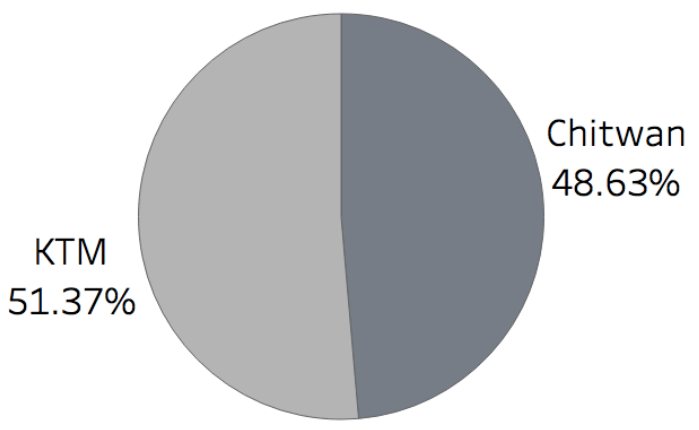

Figure 3. Distribution of the respondents according to region

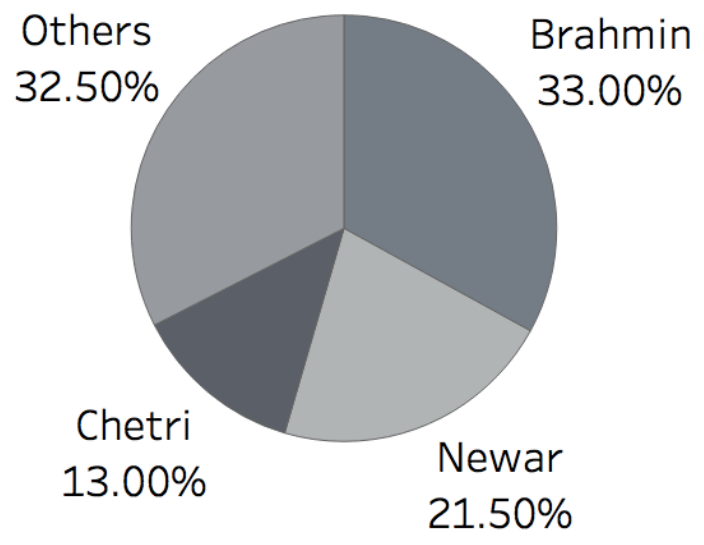

Figure 4. Distribution of the respondents according to caste 
Figure 5 shows the average values for each question item in Q1-2 asking for the present condition about economic confusion due to the political crisis using the five-point Likert scale. From Figure 5, it is understood that Q1-2.4, Q1-2.8, Q1-2.11, and Q1-2.13 represent numerical values close to 0 , compared with other items. Especially the respondents' average values of Q1-2.4 (It has become difficult to get water) and Q1-2.8 (People in your city have moved away) are very close to 0 . From this result we conclude that it was not difficult to get water and many people did not move away from the city. In addition, from Q1-2.4 and Q1-2.8, there were no situations in which the number of crimes increased, or the amount of garbage increased. Conversely, Q1-2.2, Q1-2.5, and Q1-2.10 show particularly high scores. This result indicates that cooking gas and fuel were extraordinarily hard to obtain, and the prices of goods rose. As a whole, the averages for other question items were also positive. From this result, it became clear that the political crisis widely influenced people's lives from both an individual and social-economic standpoint.

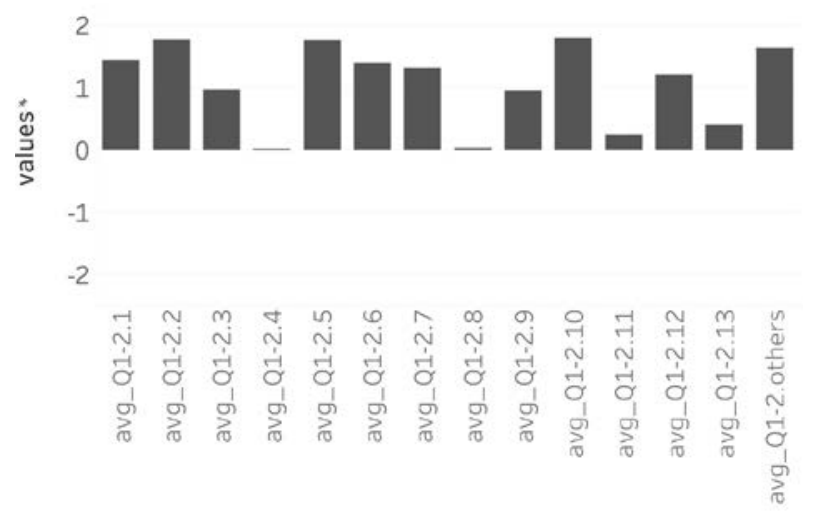

Figure 5. Average values of respondents' answers for the questions in Q1-2

Figures 6, 7, $8 \& 9$ show the results for each question item in Q1-2 when stratifying by job, sex, region and caste respectively. From these results, we found that the political crisis made Nepalese experience some inconvenience in their lives, regardless of sex, job, caste and etc. And it can also be seen that there are different tendencies within each job or region, regarding feelings and opinions for the present condition concerning the economic confusion due to the political crisis. For example, from Figure 6, in particular, observing the result of stratification by occupation, farmers show negative values for Q1-2.4 and Q1-2.8. And from Figure 9, overall, we see that people in Chitwan feel the crisis more than people in Kathmandu with the exception of water and migration issues in the impacts of economic confusion to them life from Figure 6 and Figure 9.

On the other hand, from Figure 7 and 8, no significant difference was found between males and females or any castes when stratifying by sex or caste and comparing them with the results of other factors.

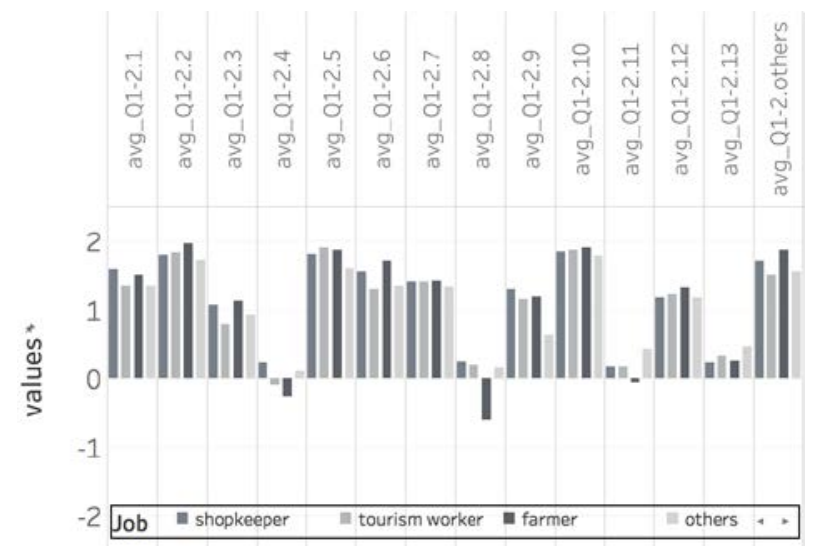

Figure 6. Average values of respondents' answers for the questions in Q1-2 when we stratified into job

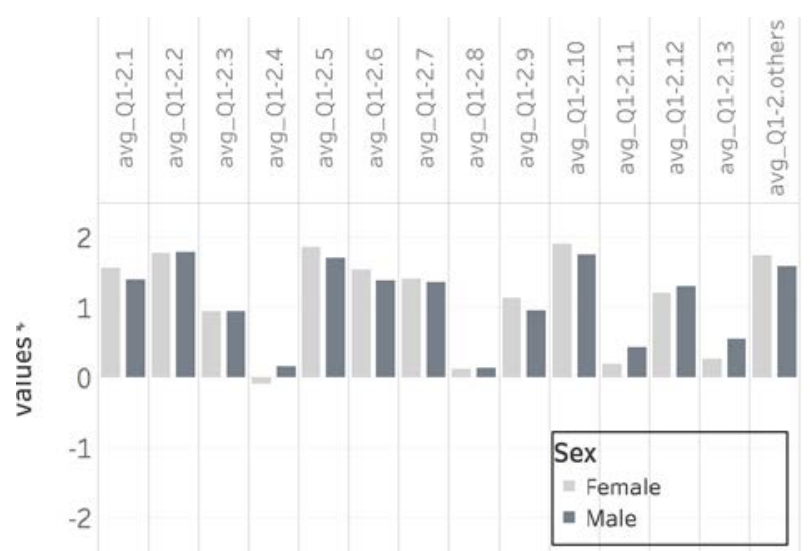

Figure 7. Average values of respondents' answers for the questions in Q1-2 when we stratified into sex
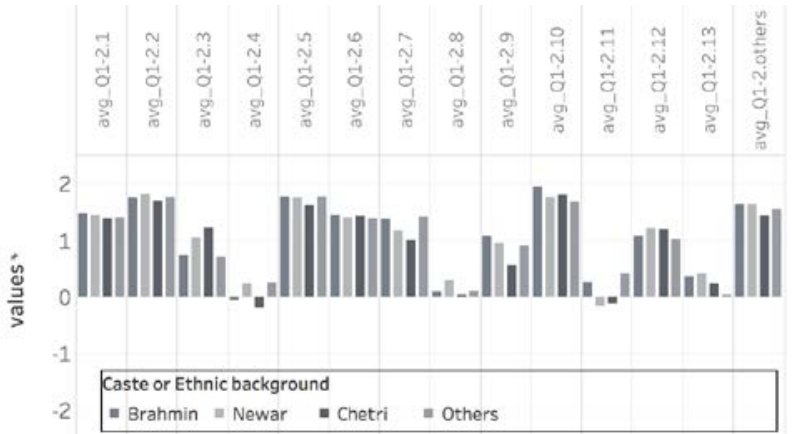

Figure 8. Average values of respondents' answers for the questions in Q1-2 when we stratified into caste

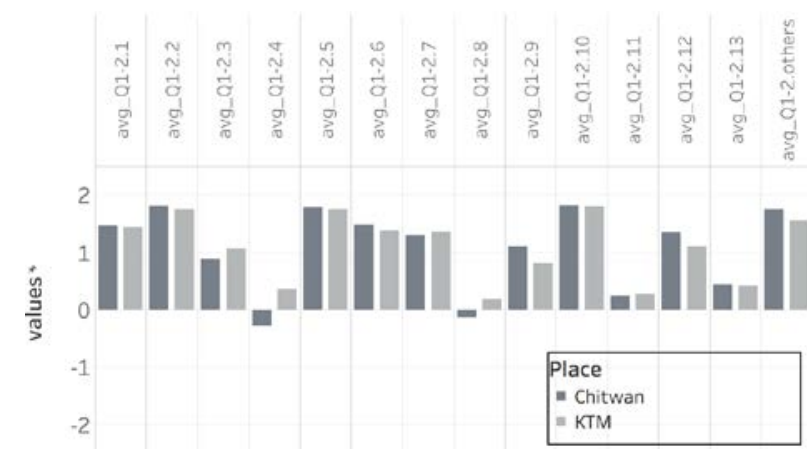

Figure 9. Average values of respondents' answers for the questions in Q1-2 when we stratified by place 
Based on the five point Likert scale, Figure 10 shows the average values of each question item in Section 2 asking what kinds of impact occurred in the Nepalese industry due to the political crisis. The Figures below represent the results of each question item in Section 2, "A" means the question items of agriculture, "T" means that of tourism and "C" means that of commerce. Looking at this result of Figure 10, we can see that the local people feel that the political crisis has had an adverse effect on the three industries considered which are agriculture, tourism and commerce. Especially tourism seems to have had the biggest adverse effect. It is thought that this is attributed to the political crisis which resulted in a negative image of Nepal from the perspective of other countries. Indeed, tourists arriving from other countries in 2015 when the political crisis occurred decreased by $32 \%$, compared with the previous year [21].

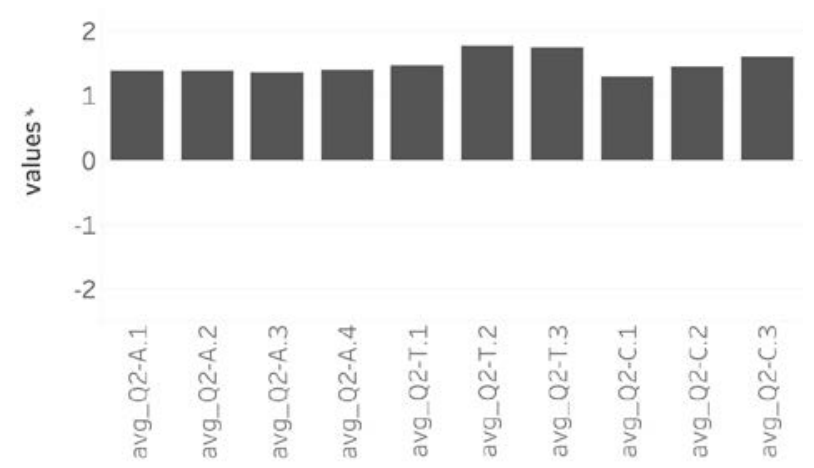

Figure 10. Average values of respondents' answers for the questions in Section 2

Figure 11 to 14 displays the results of each question item in Section 2 when stratifying by job, sex, region and caste are shown. From Figure 11 and 14, it can be seen that farmers (Figure 11) and people living in Chitwan (Figure 14) responded with higher scores for almost all the questions in Section 2. In other words, farmers and people living in Chitwan recognize that the political crisis this time had a very serious adverse effect on the Nepalese industry. In addition, compared with tourism workers and shopkeepers, there is a particularly large difference in the tendencies of the responses for agriculture. In other words, it can be thought that the political crisis made a big negative impact on agriculture compared with those people engaged in other industries. This is probably attributable to the fact that Chitwan, which is a strong farming community, depends on markets in Kathmandu and destinations in India for its income from agricultural products. However, due to the political crisis, the supply of gasoline and other fuels from India stopped, and transportation became difficult. As a result, much of the agricultural produce could not be transported, which resulted in the escalation of tension and greater difficulties for the farmers in Chitwan. Additionally, from Figure 12, regarding the differences between males and females, the results are very interesting. More Women than men indicated that the political crisis created adverse effects on the local industries. This finding points to the fact the women often take charge of domestic and agricultural work in Nepal [22],[23] and people in the agriculture sector feel the biggest influence of a political crisis. It is considered that women are more aware of the price of agricultural commodities increasing when they buy food, and thus they may have a more negative image of the political crisis. Also, from the Figure 13, depending on the caste or residence, there were no significant differences in the tendencies of the responses to the question in Section 2 .

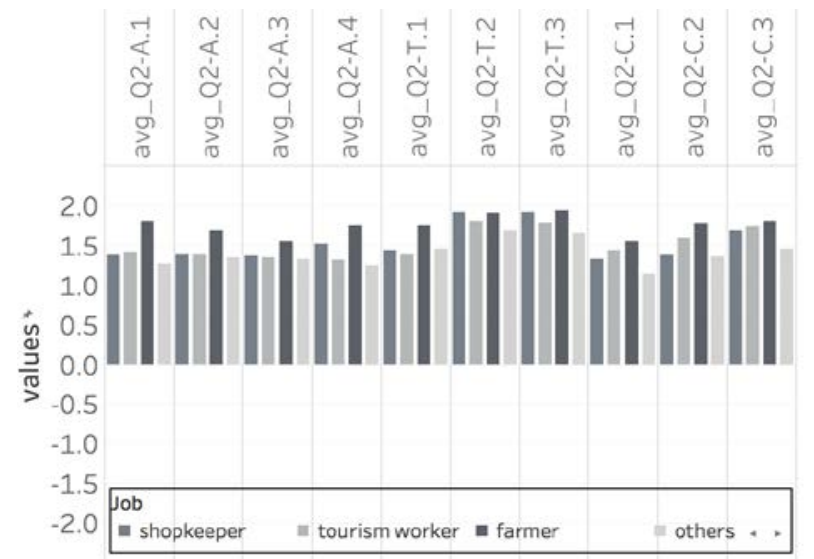

Figure 11. Average values of respondents' answers for the questions in Section 2 when we stratified by job

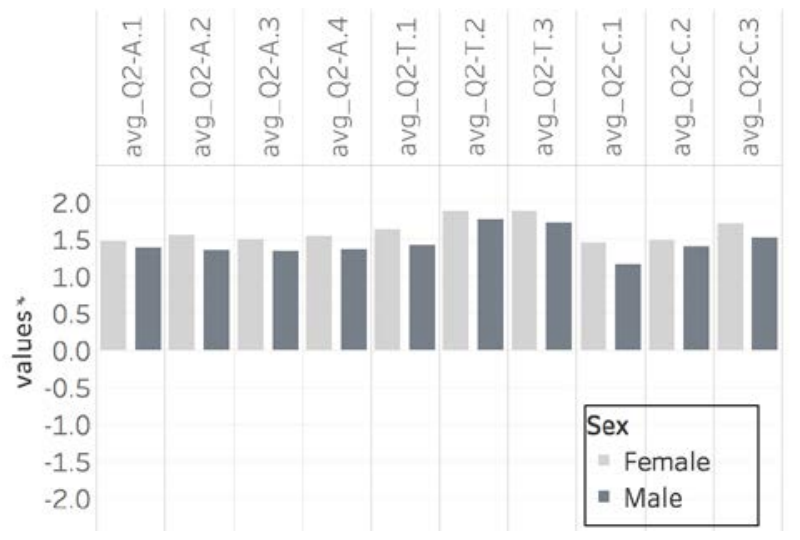

Figure 12. Average values of respondents' answers for the questions in Section 2 when we stratified into sex

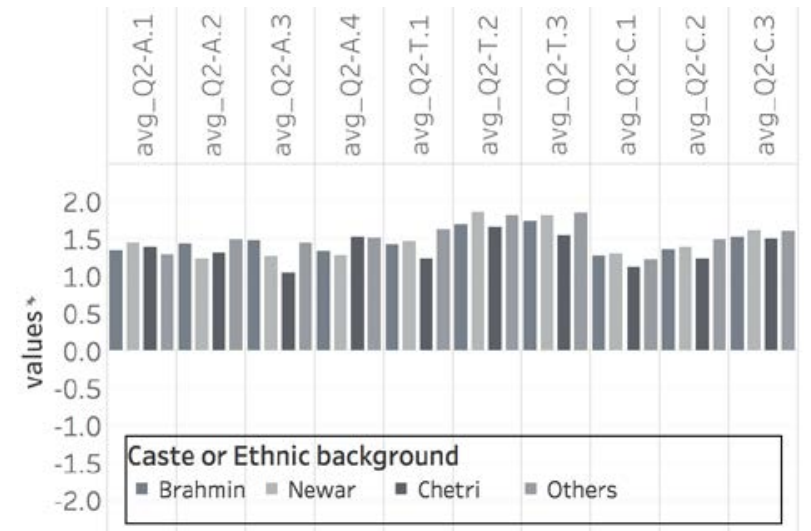

Figure 13. Average values of respondents' answers for the questions in Section 2 when we stratified into caste 


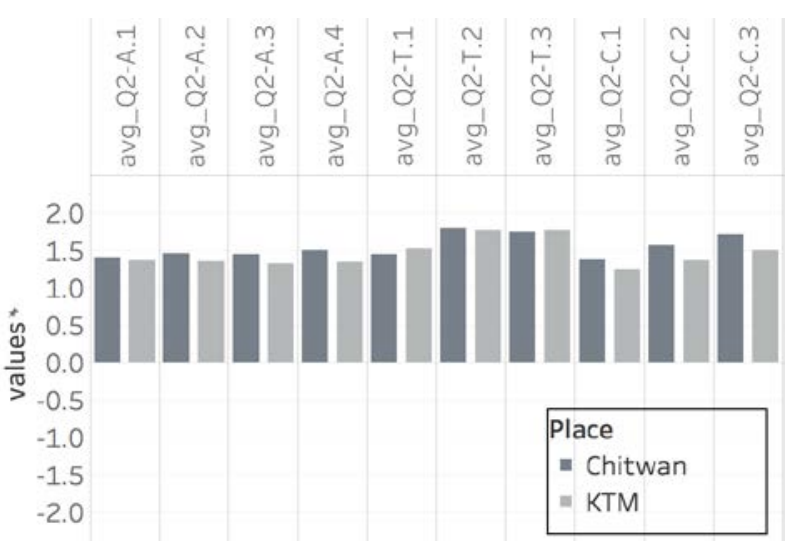

Figure 14. Average values of respondents' answers for the questions in Section 2 when we stratified into place

From Figures 15 to 19, we can see some parts of the results of Section 3 asking the knowledge about the political crisis. First of all, looking at Figure 15, we can see that the ratio of people who answered "Yes" to the question "Do you know the cause of the political crisis?" is $81.69 \%$. This infers that nearly $20 \%$ of Nepalese people may not know the reason why they cannot secure goods and fuel for their lives. We found various degrees of differences in the tendencies of responses depending on occupation, caste and region. From these results, there is a possibility that, for example, people of the Chetri caste, which easte is the lowest caste of the 3 from our survey, may face shortages of goods and other inconveniences without knowing the causes. In other words, it may suggest that the concern is low and the consciousness of the parties is lacking for the problem occurring in their country.

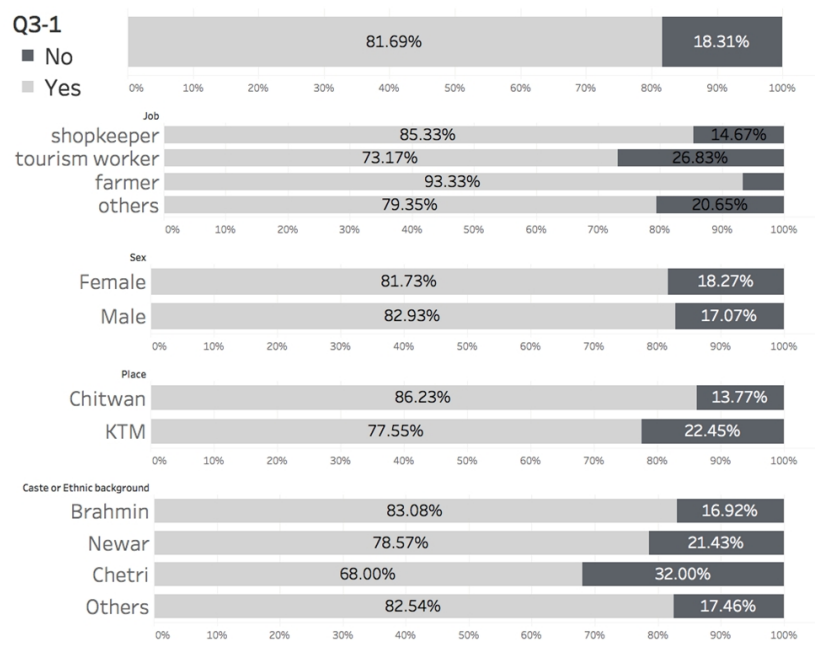

Figure 15. Distribution of the answers for the Q3-1 when we stratified into each factor

Next, looking at Figure 16, we can see that the most frequent response to the question, "Who do you think made this political crisis?" is "Government". And the next most frequent answer is "India". From this result, it is understood that there are more people who are dissatisfied with the domestic politics than the number of people who are dissatisfied with India.

\section{Ethnic grps}

\section{$7.31 \%$}

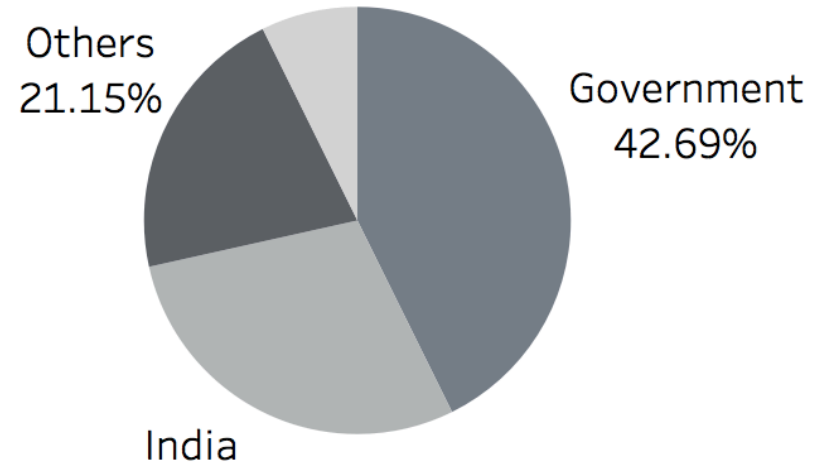

\section{$28.85 \%$}

Figure 16. Distribution of the answers for the Q3-2

Next, looking at Figure 17, we can find that $92.47 \%$ of respondents answered "Yes" to the question, "After this crisis ends, do you think a political crisis like this will happen again in the future?" In other words, even if the political crisis is resolved, most Nepalese may worry about the likelihood of similar situations occurring. And, even when stratified by job, sex, region and caste, approximately $90 \%$ of people are still concerned about recurrence.

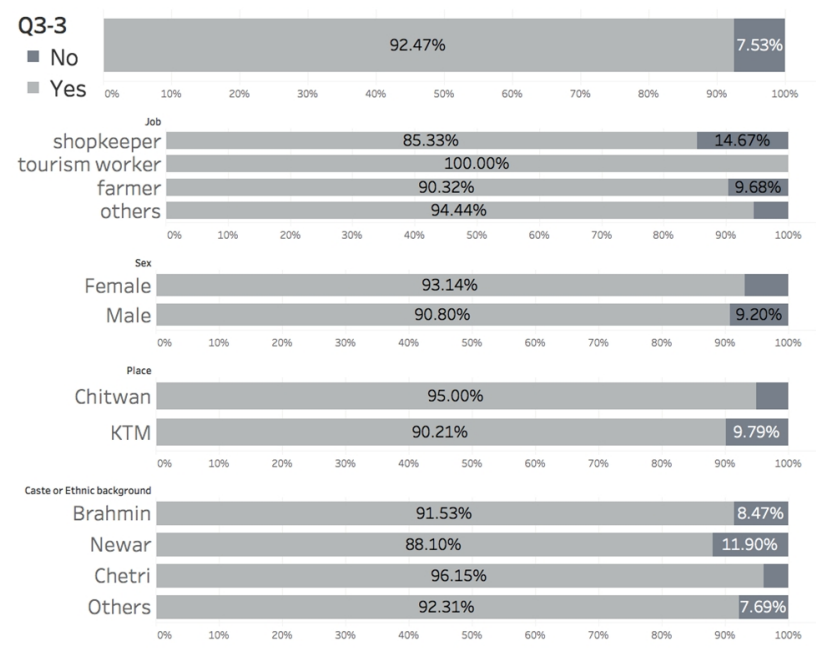

Figure 17. Distribution of the answers for the Q3-3 when we stratified into each factor

In addition, From Figure 18, we can know that over 50\% of people think that they have no power to prevent the next crisis in the future. This was especially noticeable in the tourism industry where $80 \%$ of the people responded that there is nothing they can do. From Figure 15, there is a tendency that people in the tourism industry do not grasp the cause of the political crisis, hence this can be inferred as the reason they believe they cannot take action. 
Additionally, we can find that over $65 \%$ of the people belonging to the Chetri caste, which is a relatively low caste, believe they cannot take action. This result also suggests that differences in castle consciousness are caused by the difference in caste.

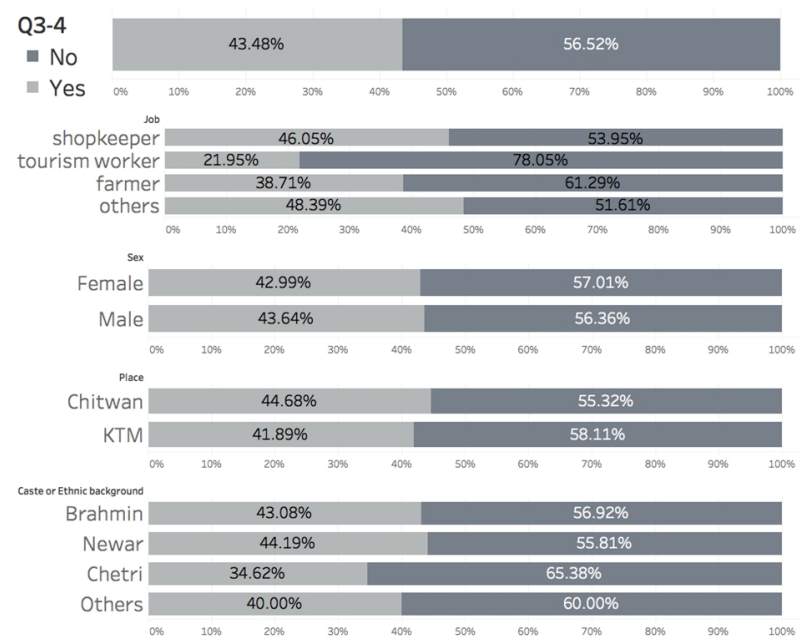

Figure 18. Distribution of the answers for the Q3-4 when we stratified into each factor

Next, looking at Figure 19, nearly 80\% of people replied that the government should take responsibility for any political crisis that may occur in the future. As shown in Figure 16, with regard to the cause of this political crisis, only $40 \%$ answered "Government". It means that there are many people who think that although the crisis is not caused by the government, responsibility should be taken by the government. Although many people answered "I know the cause of the political crisis" (Q3-1), in fact they do not understand the cause well.

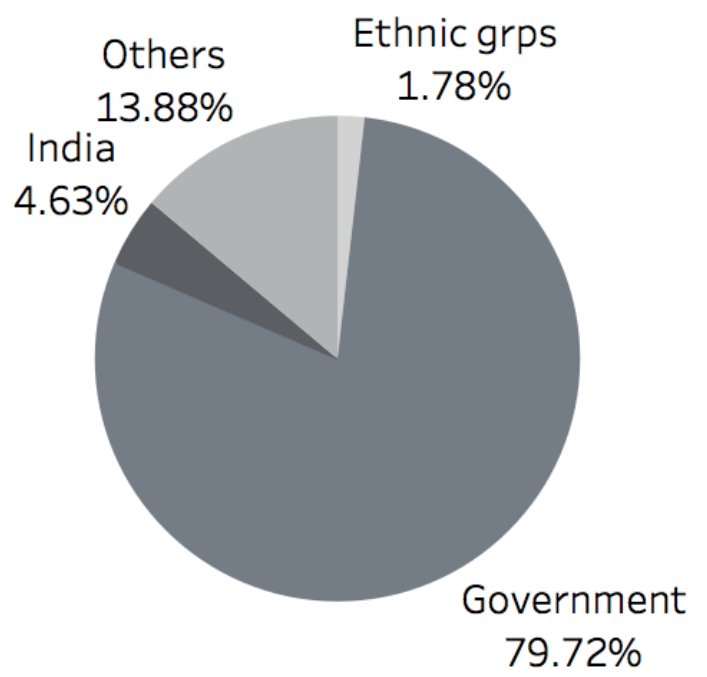

Figure 19. Distribution of the answers for the Q3-12

\section{Suggestions}

Through this field interview, various aspects surrounding the situation connected to the political crisis became clear. Among them, the following stand out.
- The political crisis exerted a great influence throughout Nepal. Almost every Nepalese experienced some inconvenience in their lives, regardless of sex, job, caste and etc.

- People living in Chitwan, and in particular farmers, tend to feel strongly the influence of the political crisis both in their personal economic situation, as well as in the social economic environment, compared to those living in Kathmandu or those whose jobs are shopkeepers or tourism staff..

- Compared to other industries, the tourism industry is recognized as the industry that is the most affected by the political crisis.

- Farmers tend to feel a larger influence from the political crisis in managing their own industry compared to people in other industries.

- Nearly $20 \%$ of Nepalese people face inconveniences, such as difficulty in getting goods and fuel supplies without knowing the cause of the political crisis well.

- Depending on job, caste and region, some differences in the knowledge level of why the political crisis occurred were identified. In particular, depending on the caste, a large difference in the knowledge level of the ongoing political crisis and in the parties' awareness to political crisis at that time was identified.

- $\quad$ Regardless of the cause, most Nepalese people tend to think that the government should take responsibility for the political crisis.

Based on these results, we propose several suggestions in various fields. The first suggestion is to make tourism in Nepal a strong industry that is not affected by the factors such as the political crisis. In Nepal, tourism is still in the developing stages; therefore, the number of tourists may drastically decrease due to factors such as a political crisis [21],[24]. It is therefore necessary to form a strong tourism industry that is not largely influenced by these factors. Arai [25] states that by strengthening the tourism industry in Nepal has a positive ripple effect occurring in the other industries, such as agriculture. As the number of tourists increases, domestic consumption becomes extremely intense. As a result, demand for agriculture and commerce will also increase, and a virtuous circle will occur in the entire industry of the country. Based on these findings, it is thought that even if a political crisis recurs in the future, it can reduce the impact on each industry by strengthening the tourism industry which is considered to have the greatest impact at this time.

The second proposal is to extend the transportation route. The ongoing political crisis at that time occurred because the transportation route to India was closed. In other words, because it depends too much on India, it has developed into a big problem in which the entire population are inconvenienced. In addition, from this survey, it became clear that most citizens think that a crisis will occur again in the future. Considering the experience of this political 
crisis, if Nepal extends the transportation route, we think that damage can be reduced even if a similar crisis occurs next time. And if this can be realized, even if the political crisis reoccurs, it will lead to securing domestic convenience and contributing to the realization of the first proposal.

The third proposal is to listen to the public opinion. From our survey regarding the ongoing political crisis at that time, most of the Nepalese population thought that it was responsible for the government. In fact, it may be difficult to reflect the opinions of all people in politics in a multinational country like Nepal. However, we believe that the policies implemented after the referendum, etc., and the policies pushed by the government are different from the people's consent. In addition, by doing so, the proportion of the people who answer "government is responsible / the government should take responsibility" will decrease.

The final suggestion is to standardize the knowledge level of all the Nepalese. This also leads to raising awareness of the parties of the people living in Nepal. Based on our research, $20 \%$ of Nepalese are inconvenienced in their daily life by the political crisis without knowing its cause. In addition, they think that there is nothing they can do by themselves. In other words, it is thought that there are many passive citizens [26]. However in this case, no matter what kind of mistake the government makes, a lack of knowledge and subsequent suppression of the power of the people will not help. Therefore, the experience of this political crisis should be an opportunity to improve the knowledge level of all Nepalese [27],[28]. By strengthening education and the enlightenment of activities, it is thought that there is a possibility that citizens will be able to not only rely on the government, but also take action by themselves to prevent future recurrence.

\section{Conclusions}

In this study we investigated the various influences impacting the lives of Nepalese people during the period of the political crisis, using an interview questionnaire. Moreover, the differences of the tendencies between demographic attributes of respondents were compared and analyzed, stratifying by job, sex, caste and region. Through this investigation, the realities of the problem are clarified. In addition, we considered suggestions for the problem at the time. As the final suggestion, we point out that "strengthening the tourism industry", "extending the transportation route", "listening to the public opinion" and "raising the standard of knowledge and awareness of the parties for all Nepalese" are four ways to address this issue.

In the future, it is desirable to conduct further research to investigate the change of opinions of local people once the political crisis is resolved. If the political crisis recurs in the future in Nepal, it is important to identify how the past experience can be used to address problems in the future.

\section{Acknowledgements}

We are very grateful to experts for their appropriate and constructive suggestions to improve this research paper. The authors would like to acknowledge Mr. Ujjwal Upadhyay, National College, Kathmandu, Mr. Shuji Yagyu, Graduate University for Advanced Studies, and Ms. Manita Shresta, Kanagawa Committee for UNICEF, for their useful suggestions and cooperation for our research. This field interview could be conducted by support of the students from National College. We would like to thank all students who supported our research.

In addition, we are very grateful to Ms. Yuri Nishio, Waseda University, Ms. Satomi Ito, University of Sacred Heart and the members of Nepal Japan Project team for their helpful comments for this research. A part of this study was supported by JSPS KAKENHI Grant Number 25301002.

\section{Appendix}

\section{Appendix 1}

Below, we post the questionnaire survey items.

Date: / No: Interviewer:

Place:

\section{Questionnaire about political crisis and its impact on economic and social environments in Nepal}

Name:

$$
\text { Sex: } \square \text { male } \square \text { female Age: ....... }
$$

Profession: Caste or Ethnic background:

Duration of residence: Yearly income: 


\section{Q1: Question for the present condition (about economic confusion by political crisis)}

1-1 Do you think that you were affected by economic confusion caused by the political crisis (and its impact to economic and social environment)? Yes No

1-2 Please give us your ideas about the impacts of economic confusion to your life.

(-2=Strongly Disagree; $-1=$ Disagree; $0=$ Unsure; +1=Agree; $+2=$ Strongly Agree)

\begin{tabular}{|c|c|c|c|c|c|}
\hline \multicolumn{6}{|l|}{ About private economic } \\
\hline 1. Your family income has decreased. & -2 & -1 & 0 & +1 & +2 \\
\hline 2. It has become difficult to get gasoline. & -2 & -1 & 0 & +1 & +2 \\
\hline 3. It has become difficult to get electricity. & -2 & -1 & 0 & +1 & +2 \\
\hline 4. It has become difficult to get water. & -2 & -1 & 0 & +1 & +2 \\
\hline 5. It has become difficult to get gas. & -2 & -1 & 0 & +1 & +2 \\
\hline 6. Your life has become poorer. & -2 & -1 & 0 & +1 & +2 \\
\hline \multicolumn{6}{|l|}{ About social economic } \\
\hline 7. Goods have not been circulated in your city. & -2 & -1 & 0 & +1 & +2 \\
\hline 8. People in your city have moved away. & -2 & -1 & 0 & +1 & +2 \\
\hline 9. The number of cars on the road has decreased. & -2 & -1 & 0 & +1 & +2 \\
\hline 10. The price of goods has increased. & -2 & -1 & 0 & +1 & +2 \\
\hline 11. The amount of crime has increased. & -2 & -1 & 0 & +1 & +2 \\
\hline 12. The number of unemployed people has increased. & -2 & -1 & 0 & +1 & +2 \\
\hline 13. The garbage in your city has increased. & -2 & -1 & 0 & +1 & +2 \\
\hline
\end{tabular}

- Has your life been affected by economic confusion by the political crisis? (from -2 to +2 )

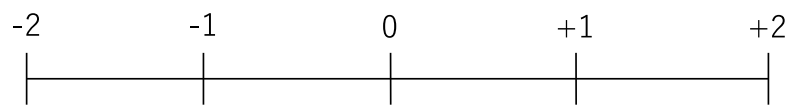

- What is the daily necessity you are most in need of now for your life? (free)

- What had the biggest impact on your life? Please answer three factors from the above items $1 \sim 13$ in Q1. (for NC: please write number) If you want to answer with another point, you can answer "others( • • • )".

\section{Q2: About industry (about economic confusion by political crisis)}

What kind of influence has happened to each industry by economic confusion caused by political crisis? (-2=Strongly Disagree; $-1=$ Disagree; $0=$ Unsure; $+1=$ Agree; $+2=$ Strongly Agree $)$

\begin{tabular}{|c|c|c|c|c|c|c|}
\hline \multirow{3}{*}{ 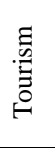 } & 1. The number of Nepali tourists has decreased in your city. & -2 & -1 & 0 & +1 & +2 \\
\hline & 2. The number of foreign tourists has decreased in your city. & -2 & -1 & 0 & +1 & +2 \\
\hline & 3. Tourism has declined in your city. & -2 & -1 & 0 & +1 & +2 \\
\hline \multirow{4}{*}{ 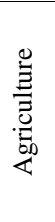 } & 1. It has become difficult to harvest farm products. & -2 & -1 & 0 & +1 & +2 \\
\hline & 2. It has become difficult for farmers to sell their products to Nepali people. & -2 & -1 & 0 & +1 & +2 \\
\hline & $\begin{array}{l}\text { 3. It has become difficult for farmers to sell their products in tourist shops or to the } \\
\text { hotels for foreigners. }\end{array}$ & -2 & -1 & 0 & +1 & +2 \\
\hline & 4. The agriculture has declined in this year. & -2 & -1 & 0 & +1 & +2 \\
\hline \multirow{3}{*}{ 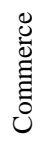 } & 1. The number of Nepali shoppers has decreased. & -2 & -1 & 0 & +1 & +2 \\
\hline & 2. The number of foreign shoppers has decreased. & -2 & -1 & 0 & +1 & +2 \\
\hline & 3. The commerce has declined. & -2 & -1 & 0 & +1 & +2 \\
\hline
\end{tabular}


- What kind of industry has been received the biggest impact of economic confusion due to the political crisis?

atourism $\quad \square$ agriculture $\quad \square$ commerce $\quad \square$ others

\section{Q3: About political crisis}

About political crisis, please answer the following questions.

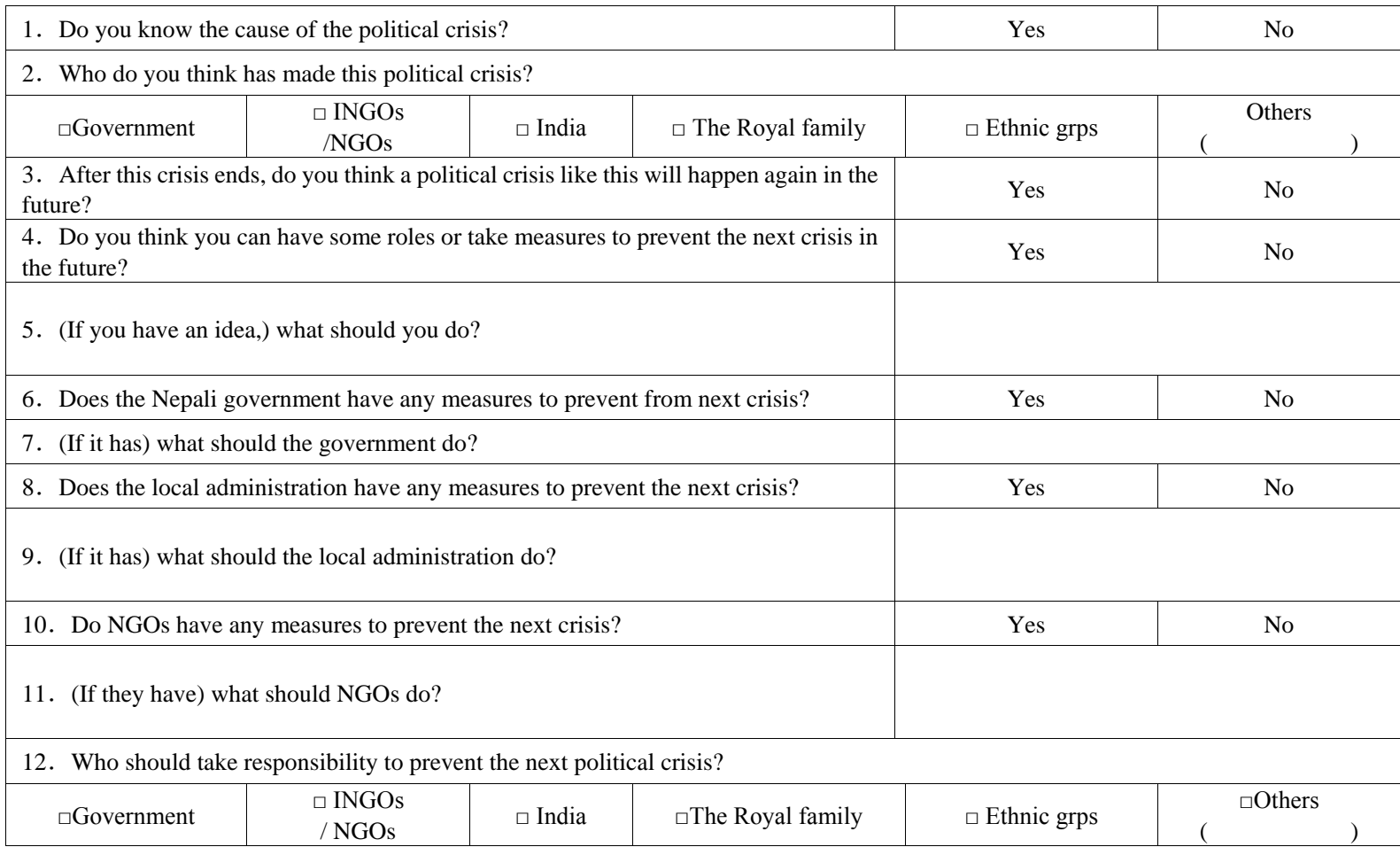

\section{Q4: Free answer}

If you have more ideas that you want to say about the political crisis, please write your ideas.

Thank you for your corporation! 


\section{Appendix 2}

Below, we post the results of the questionnaire items which we could not post in this paper.

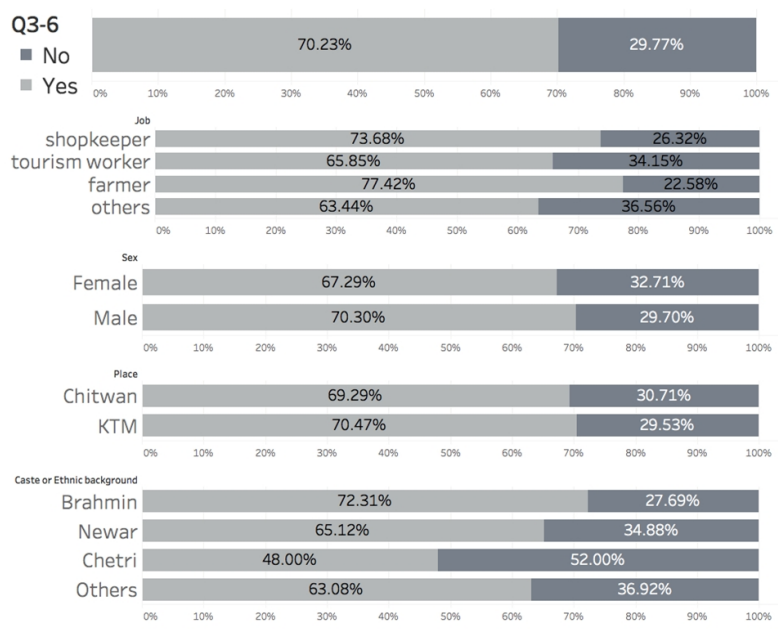

Figure 20. Distribution of the answers for the Q3-6 by all answers when we stratified into place

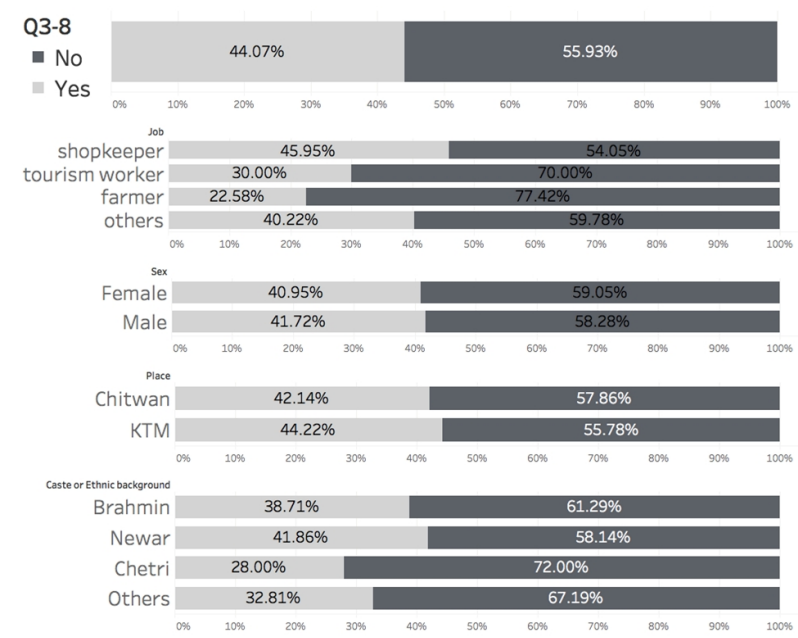

Figure 21. Distribution of the answers for the Q3-8 by all answers when we stratified into place

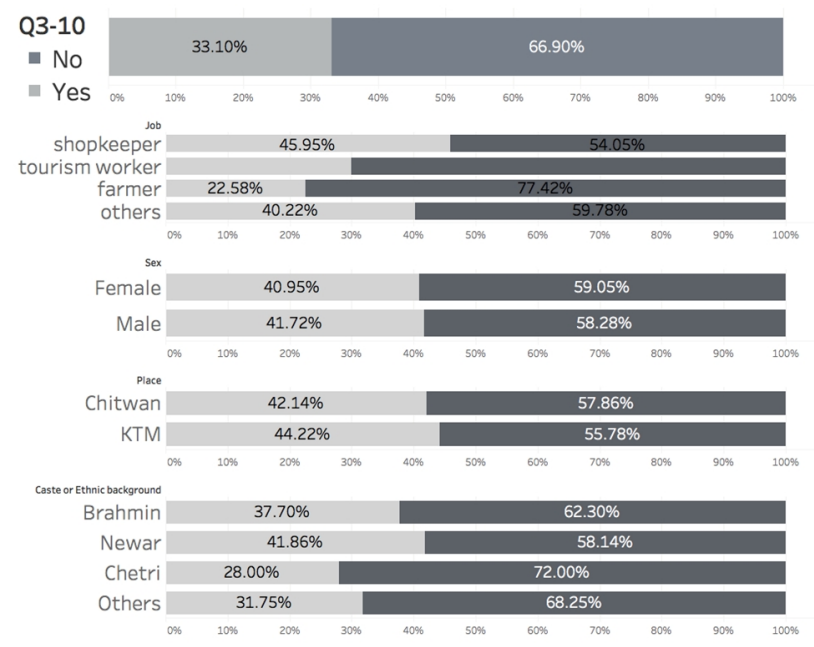

Figure 22. Distribution of the answers for the Q3-10 by all answers when we stratified into place

\section{REFERENCES}

[1] M. Didier, B. Grauvogl, A. Steentoft, S. Ghosh, B. Stojadinovic, SEISMIC RESILIENCE OF THE NEPALESE POWER SUPPLY SYSTEM DURING THE 2015 GORKHA EARTHQUAKE, World Conference on Earthquake Engineering, 16WCEE 2017 Santiago Chile, Vol. 16, 2017.

[2] S. Giri, K. Risnes, O. Uleberg, T. Rogne, S. K. Shrestha, O. P. Nygaard, R. Koju, E. Solligard, Impact of 2015 earthquakes on a local hospital in Nepal: A prospective hospitalbased study, Ganesh Dangal, National Academy of Medical Sciences, 2018.

[3] L. B. Adhikari, U. P. Gautam, B. P. Koirala, M. Bhattarai, T. Kandel, R. M. Gupta, C. Timsina, N. Maharjan, K. Maharjan, T. Dahal, The aftershock sequence of the 2015 April 25 Gorkha-Nepal earthquake, Geophysical Journal International, Vol. 203, No. 3, 2119-2124, 2015.

[4] H. Varum1, A. Furtado, H. Rodrigues, J. Dias-Oliveira, N. Vila-Pouca, A. Arede, Seismic performance of the infill masonry walls and ambient vibration tests after the Ghorka 2015, Nepal earthquake, Vol. 15, No. 3, 1185-1212, 2017.

[5] A. Muacevic, J. R. Adler, Surgical Management of Musculoskeletal Injuries after 2015 Nepal Earthquake: Our Experience, Cureus Publishing Beyond Open Access, Vol. 7, 2015.

[6] H. Ojha, After two devastating earthquakes -a blockade on its border presents Nepal with another humanitarian crisis-, The India-Nepal Crisis, The Diplomat, 2015.

[7] N. Koirala, G. Macdonald, Nepal is in crisis, and it has nothing to do with the earthquake. Here's what you need to know., Democracy Dies in Darkness, 2015.

[8] S. Khalid, Nepal's ethnic Madhesis fight for dignity and equality - People from the country's southern region say they will continue their struggle against domination by hill people.-, ALJAZEERA, 2016.

[9] K. D. Joshi, C. Conroy, J. R. Witcombe, Agriculture, seed, and innovation in Nepal: Industry and policy issues for the future, INTERNATIONAL FOOD POLICY RESEARCH INSTITUTE, 2012.

[10] S. K. Adhikary, Nepal Country Report: the Technical Advisory Committee and Governing Board meeting of the Asian and Pacific Centre for Agricultural Engineering and Machinery, Beijing, 2003.

[11] M. R. Manavazhi, D. K. Adhikari, Material and equipment procurement delays in highway projects in Nepal, International Journal of Project Management, Vol. 20, No. 8, 627-632, 2002.

[12] Human innovation, Points when designing questions, On available from http://humani.jp/wp/survey/?page_id=111\# YesNo

[13] K. Stiles, What Works Better In Your Survey - Scales Or Yes/No Styled Questions?, On available from https://www. surveycrest.com/blog/scales-or-yes-no-questions/ 
[14] M. Singh, India and Nepal: neighbours trapped by apprehensions. The Hindu Centre for Politics and Public Policy 30 June 2016, On available from http://www.thehinducentre.com/multimedia/archive/02922/ 109_India_and_Nep_2922002a.pdf

[15] S. S. Budhathoki, H. Gelband, Manmade earthquake: the hidden health effects of a blockade-induced fuel crisis in Nepal, BMJ Glob Health, 2016.

[16] A. M. Gurung, THE MADHESI MOVEMENT IN NEPAL: A STUDY ON SOCIAL, CULTURAL AND POLITICAL ASPECTS, 1990-2015, In Partial Fulfilment of the Requirement for the Degree of Master of Philosophy, 2017.

[17] M. C. Basri, A Tale of Two Crises: Indonesia’s Political Economy, JICA Research Institute, No.57, 2013.

[18] T. Phaktanakul, T. Chieocharnpraphan, A solution to Thailand's political crisis, Australian Political Studies Association Annual Conference, 2015.

[19] DARTMOUTH JOURNEYS, Nepal Earthquake Case Studies, On available from https://journeys.dartmouth.edu/ NepalQuake-CaseStudies/caste-based-inequality/

[20] IPFS, Caste system in Nepal, On available from https://ipfs.io/ipfs/QmXoypizjW3WknFiJnKLwHCnL72ve dxjQkDDP1mXWo6uco/wiki/Caste_system_in_Nepal.html

[21] S. Durbar, Nepal Tourism Statistics 2017, Ministry of
Culture, Tourism \& Civil Aviation , Government of Nepal, 2016.

[22] International Labour Organization, No easy exit - Migration bans affecting women from Nepal, Fundamental Principles and Rights at Work (FUNDAMENTALS): Labour Migration Branch (MIGRANT) - Geneva: ILO, 2015.

[23] CARE International, Gender relations in Nepal Overview, On available from https://care.ca/sites/default/files/files/RG A\%20Overview\%20Nepal_Final.pdf

[24] S. Durbar, Nepal Tourism Statistics 2017, Ministry of Culture, Tourism \& Civil Aviation , Government of Nepal, 2016.

[25] S. Dhungana, Nepal again fails to draw in one million tourists, The Himalayan Times, 2017.

[26] T. Arai, M. Goto, A Survey on Present Tourism in Nepal and Its Ripple Effects on Other Industries, Environment and Ecology Research, Vol. 5, 467-475, 2017.

[27] T. Take, Factors of social movement and rebellion in Nepal, JICA Research Institute, 2014.

[28] D. R. Parajuli, T. Das, Performance Of Community Schools In Nepal : A Macro Level Analysis, International Journal of Scientific and Technology Research, 2014.

[29] S. Singh, E. Bøhler, K. Dahal, E. Mills, The State of Child Health and Human Rights in Nepal, PLOS Medicine, 2006. 